\begin{tabular}{|c|l|}
\hline Title & Surface charge dominated protein absorption on hydrogels \\
\hline Author(s) & $\begin{array}{l}\text { Guo, Honglei; Uehara, Y uto; Matsuda, Takahiro; Kiyama, Ryuji; Li, Long; A hmed, Jamil; Katsuyama, Y oshinori; } \\
\text { Nonoyama, Takay uki; Kurokawa, Takay uki }\end{array}$ \\
\hline Citation & $\begin{array}{l}\text { Soft Matter, 16(7), 1897-1907 } \\
\text { https://doi.org/10.1039/C9SM01999E }\end{array}$ \\
\hline Issue Date & 2020-02-21 \\
\hline Doc URL & http://hdl.handle.net/2115/80471 \\
\hline Type & article (author version) \\
\hline Additional Information & There are other files related to this item in HUSCAP. Check the above URL. \\
\hline File Information & Protein adsorption full paper.pdf \\
\hline
\end{tabular}

Instructions for use 

. 28 9

\section{Surface charges dominated protein absorption on hydrogels}

Honglei Guo ${ }^{\mathrm{a}, \mathrm{b}, \mathrm{cl}}$, Yuto Uehara ${ }^{\mathrm{d}, 1}$, Takahiro Matsuda ${ }^{\mathrm{a}}$, Ryuji Kiyama ${ }^{\mathrm{d}}$, Long Li ${ }^{\mathrm{d}}$, Jamil, Ahmed $^{\mathrm{e}}$, Yoshinori Katsuyama ${ }^{\mathrm{a}}$, Takayuki Nonoyama ${ }^{* a, b}$,Takayuki Kurokawa ${ }^{* a, b}$

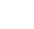

aaFaculty of Advanced Life Science, Hokkaido University, Sapporo, 001-0021, Japan

${ }^{b}$ Global Station for Soft Matter, Global Institution for Collaborative Research and Education, Hokkaido University, Sapporo, Japan

${ }^{c}$ School of Chemical Engineering and Technology, Sun Yat-sen University, ZhuHai, 519082, China

${ }^{\mathrm{d}}$ Graduate School of Life Science, Hokkaido University, Sapporo, 001-0021, Japan

${ }^{\text {e}}$ Chemistry Discipline, Khulna University, Khulna, 9208, Bangladesh

* Corresponding author. Laboratory of Soft \& Wet Matter, Faculty of Advanced Life Science, Hokkaido University, Sapporo, 001-0021, Japan. Tel: +81-11-706-9011 E-mail address: nonoyama@sci.hokudai.ac.jp,kurokawa@sci.hokudai.ac.jp ${ }^{1}$ These authors contributed to the work equally and should be regarded as co-first authors. (9) 0 1 2 23 4 5 26 7 


\section{Abstract}

Candidate materials towards soft tissue engineering require anti-fouling materials that are biocompatible, protein anti-fouling, and mechanically flexible. Conventional hydrogels having more than $70 \mathrm{wt} \%$ water are available to design with these criteria in mind. However, some of hydrogels are difficulty to apply hydrogels in internal body organs, because some undesirable proteins absorption on their surfaces. Previously, due to the lack of an effective method in observing the true charge densities of hydrogels, the reason why electrostatic interactions dominate protein absorption behavior is still unclear. In this work, we adopt the microelectrode technique (MET) to study the electrical potential of hydrogels that having negative, positive and neutral potentials, and demonstrate the protein absorption behavior on those hydrogels. The results show that the MET is an effective method to obtain the surface charge densities of various hydrogels.Furthermore, the amount of proteins absorbed to the gel is quantified by the charge density of hydrogels. These results indicate that the electrostatic absorption was quantitatively dominated by a combination of the charge density of hydrogels and the overall charges of proteins. With the knowledge obtained in this work, the effect of surface charges in a hydrogel on protein absorption could be well understood, and this result could be prospective to promote the application of hydrogel in tissue engineering. 1 (1)

\section{3} 54 55 6 7

\section{Introduction}


Recently, many candidate materials are prepared for tissue engineering applications, such as fibers ${ }^{1,2}$, polymer brushes ${ }^{3}$ and so on. Among them, the studies on hydrogelsdraw much attention due to their excellent candidate biomaterials for soft tissue engineering, such as drug delivery ${ }^{4}$, biosensor platform application ${ }^{5}$, artificial skin $^{6}$ and cartilage ${ }^{7}$. During the application of those hydrogels into tissue engineering, undesirable accumulation of proteins on hydrogel surfaces is a serious problem for neurological pathologies ${ }^{8}$, molecular symptom of aging ${ }^{9}$ and implanted device activities ${ }^{10}$. Previously, the preparation of anti-fouling materials and coatings have been conducted for many years in order to solve the proteins accumulation on the surface of materials. Traditionally, surface modification or coating the gel surface have been used to reduce protein absorption, such as polyethylene glycol (PEG) based coating ${ }^{11,12}$, polymer brush ${ }^{13}$, tuning surface roughness ${ }^{14}$, and zwitterionic poly(carboxybetaine methacrylate) (PCBMA) molecules modified silica hydrogels ${ }^{15}$. Instead of modification or coating, antifouling hydrogels has been made and found to prevent biofouling. The most widely investigated materials come from the PEG family of molecules ${ }^{16-18}$, poly(hydroxyethyl methacrylate) (PHEMA) hydrogel ${ }^{19}$ and poly(vinyl alcohol) (PVA) hydrogels ${ }^{20}$. More recently, much effort had gone into the development of novel protein antifouling materials, for example, charged but electrically neutral hydrogels, polyampholyte (PA) hydrogels ${ }^{21}$ and polyzwitterionic hydrogels ${ }^{22}$, to prevent the settlement of fouling proteins. In addition, some charged hydrogels, such as negatively charged hydrogels, also show antifouling behavior to negatively charged fibrinogen proteins ${ }^{23}$.

To develop suitable biomaterials for the tissue engineering applications, the understanding of antifouling behaviors is required. Although it has been proposed that the general antifouling materials should be electrically neutral, hydrophilic, and possess hydrogen bond acceptors but not hydrogen bond donors ${ }^{24}$, antifouling materials having those three characters were very few. In order to develop absolutely antifouling materials, both fouling and antifouling behavior should be deeply understood. It is generally accepted that the surface electric repulsive forces prevent solute deposition and thus reduce the fouling ${ }^{14}$. By changing the molar ratios of two oppositely charged 
monomers, Liu and Han et $\mathrm{al}^{25}$ found that negatively charged copolymer hydrogels exhibited relatively low absorption of the negatively charged bovine serum albumin (BSA) proteins and algae in comparison to the positively charged and neutral double network (DN) hydrogels. Previously, Gong et al. ${ }^{26}$ found that the electrostatic force dominates the protein diffusion process by accelerating or hindering proteins into the hydrogel. Meanwhile, John et al. ${ }^{27}$ also pointed out that the contribution of electrostatic effect to protein absorption depends on protein charge, gel charge density, and solution ionic strength. Similarly, Lyon et al. ${ }^{28}$ found that microgels containing high charged acrylic acid (AAc) groups are capable of loading extremely high concentrations of proteins, beyond the solubility limit of the protein in aqueous media. All of those studies infer that the electrostatic interaction dominates the protein diffusion and absorption on the hydrogel surface.

Measurement of the electrostatic interaction between hydrogels and proteins is the major criteria to understand the protein absorption. Although the charge densities of polyelectrolyte gels could be calculated from in-feed monomer concentration, the true charge density is quite different from the calculation due to the decrease of counterions activity $^{29}$. This effect is known as counterions condensation effect ${ }^{30}$, which describes that, when the charge density on polyelectrolyte chains is high, the counterions would be not only distributed in solution but also localized near polymer chain to give a decreased activity. In this case, the activity coefficient of counterions should be smaller than 1, which is the reason for being difficult to quantitatively realize the true surface charge densities of hydrogels by calculating with in-feed monomer concentration.

Finding an experimental technique for the accurate measurement of true surface charge densities of a hydrogel in microscopic level is a challenge to be taken seriously. $\zeta$-potential was often used to characterize the charge density of particles ${ }^{8}$; however, it is difficult with this method to detect the electric potential of polyelectrolyte hydrogels due to the leakage of current on the gel surface. For the confirmation our deduction, we studied the $\zeta$-potential of a polyelectrolyte gel, the measured potential values of strong polyelectrolyte PAMPS gels were found to be almost zero (Supplementary information, Fig. S1). Previously, we proposed the microelectrode technique (MET) to quantitatively 
detect the electric potential of polyelectrolyte hydrogels ${ }^{31}$. Thus, by using this method, the number of true charge densities of hydrogels could be effectively detected and the role of electrostatic effect in controlling the proteins absorption or repulsion could be clarified.

To understand the effect of potential or charge densities on protein absorption, other parameters should be considered at the same time. Even though the electrical potential of hydrogels could be tuned by varying monomer concentrations or crosslinking densities, the mesh size of hydrogels was changed as well. Generally, the mesh size of hydrogels is much larger than the hydrodynamic diameter of proteins, so the absorbed proteins would be distributed not only on the gel surface but also inside the bulk gel. Technically, it is difficult to separate the effect of mesh size and potential values of the hydrogel at the same time, because both of them are relevant to the charge densities of hydrogels. To separate those two effects on protein absorption, the electrically neutral hydrogels with different mesh sizes were firstly adopted to clarify the pore size effect, and then the correlation between surface charge densities and the amount of fouling proteins was further declared. To clarifying the protein absorption behavior on a gel, the attached proteins, which are adsorbed not only on the surface of the gel but also inside the bulk gel in 24 hours, was considered in this study.

In this study, the various hydrogels having different charges, such as positive, negative and neutral, were prepared by using free radical polymerization. Two types of commonly used proteins, BSA with an isoelectric point of 4.6 5.7 and lysozyme with an isoelectric point of 11 , were also chosen. Firstly, the electrical potentials of polyelectrolyte gels were detected by the MET. To realize the mesh size of these hydrogels, Young's modulus of those as-prepared hydrogels were measured by compression test, and swelling ratios were used for calculating mesh size at equilibrium. Secondly, the mesh size effect could be realized by preparing the neutral hydrogels with different mesh sizes and the polyelectrolyte hydrogels having almost the same electrical potentials and narrow mesh sizes distribution. Then, the fouling and antifouling behavior with both BSA and lysozyme proteins were characterized, and the number of fouling proteins was estimated by Ultraviolet-Visible (UV-Vis) spectroscopy. The 
location of absorbed proteins was further clarified by using attenuated total reflection -Fourier transform infrared spectroscopy (ATR-FTIR) and transmittance electron microscopy (TEM) observation. As a result, the amount of fouling proteins was was slightly increased with the enlarging of mesh size of hydrogels. After realizing the effect of mesh size on protein absorption, we studied the correlation between surface potential and the amount of fouling proteins. The results show that the charged hydrogels having oppositive charges of proteins showed better fouling behavior; while the charged hydrogels having the same charges of proteins showed antifouling performance. Meanwhile, the amount of absorbed proteins quantitatively depended on the measured concentration of counterions. In spite of the distribution of proteins inside the hydrogels, the fouling properties were found to be dominated by electrostatic interaction for a 24 hours measurement. This work provides an electrostatic aspect to realize protein anti-fouling and fouling behavior on positive, negative and neutral hydrogels, which are crucial for the hydrogels to be utilized in artificial implants.

\section{Materials and methods}

\subsection{Materials}

Anionic monomers, 2-acrylamido-2-methylpropane sulfonic acid sodium salt (NaAMPS) and sodium $p$-styrenesulfonate (NaSS) were purchased from Toagosei, Co. Ltd. and Wako Pure Chemical Industries, Ltd., respectively. Cationic monomer, acryloyloxyethyl trimethyl ammonium chloride (DMAEA-Q), was purchased from MT AquaPolymer. Neutral monomers, $N, N^{\prime}$-dimethyl acrylamide (DMAAm) and 2hydroxyethylacrylamide (HEA), were purchased from Junsei Chemical and Toa Gosei, Co. Ltd., respectively. Zwitterionic monomer, $N$-(Carboxymethyl)- $N, N$ '-dimethyl-2(methacryloyloxy)ethanaminium, inner salt (CDME), was a courtesy from Osaka Organic Chemical Industry, Ltd., Japan and used as received, 2-methacryloyloxyethyl phosphorylcholine (MPC) was purchased from Sigma Aldrich and used as received. $N, N^{\prime}$-methylenebis(acrylamide) (MBAA, crosslinker), 2-oxoglutaric acid (OA, initiator), and sodium chloride $(\mathrm{NaCl})$ were purchased from Wako Pure Chemical 
Industries, Ltd. All these chemicals were used as received. Albumin, from Bovine Serum Albumin Cohn Fraction (BSA, min.96\%) and lysozyme from egg white were purchased from Wako Pure Chemical Industries, Ltd. Micro Bicinchoninic Acid (BCA) protein assay kit (containing Solution A, Solution B, and Solution C) was purchased from G-Biosciences, USA, and used as received. Phosphotungstic acid and acrylic resin were purchased from Alfa Aesar and London Resin White, respectively. Deionized water was obtained by using a Millipore water system, with a minimum resistivity of $18.0 \mathrm{M} \Omega \cdot \mathrm{cm}$.

\subsection{Hydrogel preparation}

Three kinds of hydrogels, negative polyelectrolyte hydrogels, positive polyelectrolyte hydrogels, and neutral hydrogels, were synthesized by free radical polymerization initiated under UV irradiation. A precursor aqueous solution containing monomers, cross-linker (MBAA), and initiator (OA) was poured into a reaction cell consisting of two glasses spaced with $2.0 \mathrm{~mm}$ silicone rubber. Then, hydrogels were synthesized by UV irradiation for $8 \mathrm{~h}$ under argon atmosphere.

(1) Negative polyelectrolyte gels: PNaAMPS hydrogels were prepared from a precursor aqueous solution containing monomer (NaAMPS: 1.0, 1.5, 2.0, 2.5, 3.0 M), cross-linker (MBAA: 4.0 mol\% relative to NaAMPS concentration), and initiator (OA: $0.1 \mathrm{~mol} \%$ relative to NaAMPS concentration). Similar to PNaAMPS hydrogels preparation, the composition of PNaSS hydrogel was NaSS concentration of $1.0 \mathrm{M}$, MBAA concentration of $0.08 \mathrm{M}$ and $\mathrm{OA}$ concentration of $0.001 \mathrm{M}$.

(2) Positive polyelectrolyte gels: PDMAEA-Q hydrogels were prepared from a precursor aqueous solution containing monomer (DMAEA-Q: $2.0 \mathrm{M}$ ), cross-linker (MBAA: 5, 6, 7, 8, and 9 mol\% relative to DMAEA-Q concentration), and initiator (OA: $0.1 \mathrm{~mol} \%$ relative to DMAEA-Q concentration).

(3) Neutral hydrogels: PDMAAm, PMPC, PCDME, and PHEA hydrogels were separately prepared from an aqueous solution containing monomer $(2.0 \mathrm{M})$, crosslinker (MBAA: $4 \mathrm{~mol} \%$ relative to monomer concentration), initiator $(0.1 \mathrm{~mol} \%$ relative to monomer concentration). Similarly, polyampholyte hydrogel was prepared by one step polymerization. An optimized composition with a total monomer 
concentration $\mathrm{C}_{\mathrm{M}}$ of $2.5 \mathrm{M}$, a molar ratio of NaSS/DMAEA-Q $=0.52 / 0.48$, and $0.1 \mathrm{~mol} \%$ MBAA and OA relative to $\mathrm{C}_{\mathrm{M}}$ was used. ${ }^{32}$

The chemical structures of polymers in those synthesized hydrogels were shown in Fig. 1. To completely remove the residual chemicals, all of those as-prepared hydrogels were immersed and rinsed twice a day with deionized water for more than 2 weeks. It would take more than 2 weeks or 1 month for the complete removal of residual chemicals, which was confirmed by detecting the conductivity change of bath solution using a conductivity meter (FE30 KIT, Mettler Toledo). After that, the swollen hydrogels with the thickness of 2.0-5.0 mm were immersed in $\mathrm{NaCl}$ solutions of prescribed concentration for at least 2 days to reach equilibrium. The swelling ratios $(Q)$ of hydrogels are defined as the volume ratio between the as-prepared and the swollen states, $Q=V_{\text {swollen }} / V_{\text {as-prepared }}=\left(t / t_{0}\right)^{3}, V_{\text {as-prepared }}$ and $V_{\text {swollen }}$ are the gel volumes of the as-prepared and the swollen states, $t$ and $t_{0}$ are the gel thickness of the swollen and the as-prepared states respectively.

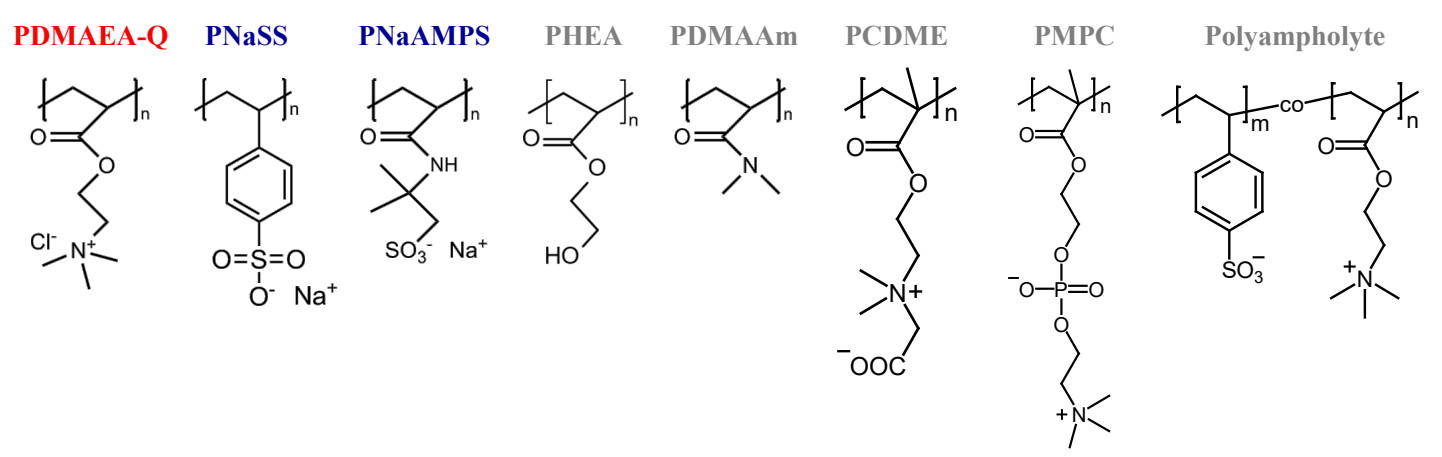

Fig. 1 Various polymer structures for different hydrogels, such as positive (red color), negative (blue color) and neutral (gray color) hydrogels.

The synthesized hydrogels were coded to $\mathrm{C}_{M}-\mathrm{C}_{M B A A}-0.1$, where $\mathrm{C}_{\mathrm{M}}$ and $\mathrm{C}_{\mathrm{MBAA}}$ represented the feed monomer concentration and molar percent of cross-linker relative to the concentration of in-feed monomers, respectively; 0.1 represented the $0.1 \mathrm{~mol} \%$ molar percent initiator relative to the concentration of in-feed monomers.

\subsection{Donnan potential $(\Delta \phi)$ of hydrogels measured by microelectrode technique (MET)} $\Delta \phi$ of hydrogels was measured by using microelectrode technique (MET), which 
has been applied routinely to measure the electric potential of the living cells ${ }^{33}$. The microelectrodes were prepared with a reversible silver/silver chloride electrode $(\mathrm{Ag} / \mathrm{AgCl})$ placed into a glass micropipette with a tip diameter $<1 \mu \mathrm{m}$. Then, the glass micropipettes were filled with $3 \mathrm{M} \mathrm{KCl}$ solution and connected to the inputs of a highimpedance intracellular preamplifier (Model 8700 Cell Explorer, Dagan). The carbon electrode was served as the reference electrode, which was placed in the bathing solution for $20 \mathrm{~min}$ before measurement. Hydrogel with the thickness of $2 \sim 5 \mathrm{~mm}$ was placed in $10^{-5} \mathrm{M} \mathrm{NaCl}$ solution. The glass microelectrode controlled by a micromanipulator (DMA-1511, Narishige) was penetrated into the hydrogel with a constant speed. The output signals were recorded with an oscilloscope in a real-time mode. All measurements were performed at $25^{\circ} \mathrm{C}$.

\subsection{Compression test}

Compression test, which was referenced to ASTM D575 Rubber Compression Testing, was performed with a universal mechanical test machine (Tensilon RTC1150A, Orientec Co.). The as-prepared hydrogels were cut into cylindrical-shaped specimens as standardized sizes (diameter $14.86 \mathrm{~mm}$, thickness $2.0 \mathrm{~mm}$ ) with a gel cutting knife. The as-prepared hydrogel specimens were compressed at a constant velocity of $0.05 \mathrm{~mm} / \mathrm{min}$ to strain $\sim 10 \%$.

\subsection{ATR-FTIR measurement}

Attenuated total reflectance FT-IR spectra were obtained with a Macro-ATR, Fourier Transform Infrared system (IRT-6600, Jasco) in the range of 4000-800 $\mathrm{cm}^{-1}$. Each spectrum was taken as the average of 128 scans at a resolution of $4 \mathrm{~cm}^{-1}$. Generally, the diamond prism (refractive index $\mathrm{n}=2.4$ at $1000 \mathrm{~cm}^{-1}$ ) was used for a depth of penetration of $2.0 \mu \mathrm{m}$ at $1000 \mathrm{~cm}^{-1}$, (angle of incidence is $\theta=45^{\circ}$, the refractive index of hydrogel is $1.53^{34}$ ) and a measured area of $2.5 \mathrm{~mm}^{2}$. Baseline correction was made automatically by Concave Rubberband method with 64 baseline points. In this experiment, PDMAEA-Q (2-9-0.1) and PNaAMPS (2.5-4-0.1) hydrogels were chosen for measurement.

\subsection{Protein absorption on gel}

2.6.1 Preparation of standards and working reagent 
(i) Preparation of diluted Albumin (BSA) and lysozyme standards

Initially, $20 \mathrm{~mL}$ BSA or lysozyme stock solution at the concentration of $0.1 \mathrm{mg} / \mathrm{mL}$ were carefully prepared by dissolving BSA or lysozyme powders into $10^{-5} \mathrm{M} \mathrm{NaCl}$ solution. Then, five diluted BSA or lysozyme standard solution with the concentration of $0.005,0.01,0.02,0.04$ and $0.05 \mathrm{mg} / \mathrm{mL}$ were separately prepared by using the above stock solution of BSA or lysozyme.

(ii) Preparation of BCA working reagent and making standard working curves BCA assay is commonly used to assess the determination of protein concentration. The principle of this method combines the well-known reduction of $\mathrm{Cu}^{2+}$ to $\mathrm{Cu}^{1+}$ by protein in an alkaline medium and a purple color formation by bicinchoninic acid. BCA working reagent is a mixture of $25 \mathrm{~mL}$ reagent $\mathrm{A}, 24 \mathrm{~mL}$ reagent $\mathrm{B}$ and $1 \mathrm{~mL}$ reagent $\mathrm{C}$. Typically, $1 \mathrm{~mL}$ BSA solution and $1 \mathrm{~mL}$ BCA reagent were mixed and then kept it at a dark place for 1 hour. After that, the protein absorbance at the wavelength of $560 \mathrm{~nm}$ was measured by UV-Vis spectroscopy. Finally, the standard working curves of both BSA and lysozyme were made. Considering the reproducibility of this experiment, the absorbance of all samples was measured within 1 hour after the dark reaction.

\subsubsection{Measurement of protein absorption on gel}

In our experiment, the hydrogel was cut to disc shape with a diameter of 14.86 $\mathrm{mm}$. Then, the hydrogel was immersed into $5 \mathrm{~mL}$ protein solution with the concentration of $1 \mathrm{mg} / \mathrm{mL}$ for 24 hours in fresh multiwell plastic plates $(35 \mathrm{~mm}$ in diameter, $18 \mathrm{~mm}$ in depth, Corning, USA). Due to the thin thickness of gel samples $(t<5$ $\mathrm{mm}$ ), the gel samples are submerged easily with $5 \mathrm{~mL}$ protein solution. After 24 hours, proteins should be distributed in solution, surface, the bulk of gel, and substrate plates. Therefore, the amount of attached protein in a gel for 24 hours could be represented by:

$$
m_{\text {gel }}=m_{\text {total }}-m_{\text {solution }}-m_{\text {plate }}
$$

The proteins located in solution, bulk gel and plates were detected as follows:

(1) $m_{\text {solution: }}$ Protein contents in solution were quantified using commercially available BCA assay kit according to the manufacturer's instructions (G-Biosciences, USA). The amount of protein in bath solution was measured by UV absorption (UV-1800, 
Shimadzu). $5 \mathrm{~mL}$ of protein reagent containing BCA working reagent was added to the test tube. The concentration of protein was plotted against the corresponding absorbance resulting in a standard curve used to determine the protein concentration for all samples.

(2) $m_{\text {plate: }}$ Similarly, the control experiments were also conducted by UV-Vis absorption method. $5 \mathrm{~mL}$ protein solution $(1 \mathrm{mg} / \mathrm{mL})$ for 24 hours in fresh multiwell plastic plates. The absorption proteins on fresh plastic plates were studied 6 times, and the weight ratio of the proteins adsorbed on plates to total proteins, $m_{\text {plate }} / m_{\text {total }}$, was $-2.0 \pm 2.6 \mathrm{wt} \%$. This value was relatively small compared to the weight ratio of the attached proteins (adsorbed on the surface or diffused into the bulk gel) to total proteins, $m_{\text {gel }} / m_{\text {total }}<12.1 \mathrm{wt} \%$. Therefore, the attached proteins on gel could be calculated from Eq. (1). The attached proteins, $m_{g e l}$, contains the proteins both on the surface and inside the bulk gel. Additionally, the gel volume and surface area were considered as invariable because the volume change of hydrogels was less than $7 \mathrm{v} / \mathrm{v} \%$ after immersing into protein solution.

\subsection{TEM observation of protein layers}

In order to characterize the distribution of the protein inside the hydrogel, transmission electron microscope (TEM) (H-7650, Hitachi) was used to observe the location of proteins along gel depth profile. Typically, the polyelectrolyte hydrogels were difficult to be prepared for TEM observation due to its fragile nature during cutting. In this study, a tough double network containing a polyelectrolyte network and a neutral network was prepared for observation. For example, after protein absorption, the first PDMAEA-Q (2-9-0.1) networks was immersed into a neutral PDMAAm (2-0.1-0.1) precursor solution to prepare a tough double network (DN) hydrogel. After that, the DN gel was cut into a cylinder shape and immersed into $1 \mathrm{mg} / \mathrm{mL}$ BSA protein solution for 24 hours. After that, samples were separately transferred into $50 \mathrm{~mL}$ phosphotungstic acid solution ( $1 \mathrm{wt} \%$ ) for 3 days to stain the proteins. In order to solidify the bulk gel, the stained hydrogels were immersed into the acrylic resin in a chamber of automatic freeze substitution system (EM AFS2, Leica Microsystems, Germany). During this process, the volume expanded from the single hydrogel to the acrylic resin hydrogel 
was less than $20 \%$. After 5 days, the blocks were cut with an ultra-microtome (EM UC7i, Leica Microsystems, Germany) and $100 \mathrm{~nm}$-thick slices were placed on the membrane supported copper mesh grid for TEM observation. The acceleration voltage of the electron gun for observation was $100 \mathrm{kV}$.

\section{$2.8 \zeta$-potential and hydrodynamic diameter measurement of protein solution}

$\zeta$-potential of protein solution was conducted with a DelsaNano HC instrument (Beckman Coulter, Brea, CA). The flow cell was thoroughly flushed with DI water, and then a $10^{-5} \mathrm{M} \mathrm{NaCl}$ solution, containing a $1 \mathrm{mg} / \mathrm{mL}$ protein solution, was injected into the flow cell. The surface was allowed to stabilize for $15 \mathrm{~min}$, and then the $\zeta$-potential was measured at least 5 times for each sample. The potential values of lysozyme and BSA proteins are $34.81 \pm 4.16 \mathrm{mV}$ and $-22.13 \pm 4.26 \mathrm{mV}$, respectively (see Supplementary information Table. S1).

The hydrodynamic diameter of the protein was measured by using ZETASIZER Nano-ZS (Malvern, U.K.). Firstly, BSA and lysozyme protein solution was prepared at the concentration from $0.1 \mathrm{mg} / \mathrm{mL}$ to $1.0 \mathrm{mg} / \mathrm{mL}$. Corresponding quartz cells were filled with $50 \mu \mathrm{L}$ sample solution. Each DLS measurement was run for five times using automated, optimal measurement times and laser attenuation settings. The hydrodynamic diameters of the proteins were shown in Fig. S2 (Supplementary information). The detail information of the proteins was summarized in Table 1.

Table 1. Parameters of BSA and lysozyme proteins. ${ }^{1} \zeta$-potential of proteins were measured by DelsaNano HC equipment, as shown in Fig. S2; ${ }^{2}$ Hydrodynamic diameter of protein, $d_{\text {protein, }}$ was detected by DLS at $10^{-5} \mathrm{M} \mathrm{NaCl}$ solution, as shown in Fig. S6; ${ }^{3}$ Molecular weight, $M_{w}$, (Hirayama, K., Akashi, S., Furuya, M., \& Fukuhara, K., Rapid confirmation and revision of the primary structure of bovine serum albumin by ESIMS and Frit-FAB LC/MS. Biochemical and Biophysical Research Communications, 1990, 173(2), 639-646. PMid:2260975.) ${ }^{4}$ isoelectric point, $\mathrm{pH}(\mathrm{I})$ and ${ }^{4}$ characteristic sizes of protein, were referenced from paper (Dirceu Pereira dos Santos, Tito Lívio Moitinho Alves, José Carlos PintoAbsorption of BSA (Bovine Serum Albuminum) and lysozyme on poly(vinyl acetate) particles, Polímeros, 2016, 26 (4), 282-290); ${ }^{5}$ Number of residue, positive and negative residues are learned from protein Data Bank Japan (https://pdbj.org/). 


\begin{tabular}{lcccccccc}
\hline Protein & ${ }^{1} \zeta$-potential $(\mathrm{mV})$ & ${ }^{2} d_{\text {protein }}(\mathrm{nm})$ & ${ }^{3} M_{w}(\mathrm{~g} / \mathrm{mol})$ & ${ }^{4} \mathrm{pH}(\mathrm{I})$ & ${ }^{4}$ Size $\left(\mathrm{nm}^{3}\right)$ & ${ }^{5} n^{\text {residue }}$ & ${ }^{5} n_{+}^{\text {residue }}$ & ${ }^{5} n_{-}^{\text {residue }}$ \\
\hline Lysozyme & $34.81 \pm 4.16$ & $1.23 \pm 0.56$ & 14,000 & 11 & $4.5 \times 3 \times 3$ & 129 & 18 & 9 \\
BSA & $-22.13 \pm 4.26$ & $8.17 \pm 0.85$ & 66,000 & $4.6-5.7$ & $14 \times 4 \times 4$ & 583 & 99 & 99 \\
\hline
\end{tabular}

\section{Results and discussion}

\subsection{Synthesis and characterization of various hydrogels with different charges}

To study the electrostatic effect to the protein absorption, we synthesize three kinds of hydrogels, positive hydrogels (PDMAEA-Q gels), negative hydrogels (PNaAMPS gels) and neutral hydrogels (PDMAAm, PHA, PCDME, PMPC, and PA gels). By changing cross-linking density or monomer concentration, different hydrogels with various charge densities and swelling ratios could be prepared. For example, the swelling ratio of swollen PDMAEA-Q gels was increased with decreasing the crosslinking density (see Supplementary information Table S2). This is because the crosslinker is a bond that links one polymer chain to another, so a high concentration of cross-linkers could restrict chains separation and thus decrease the swelling ratio of hydrogels. Those swollen hydrogels, possessing different swelling ratios and charge densities or electrical potentials, could be effectively detected by using microelectrode technique (MET). As shown in Fig. 2 (a), the electrical potential of three typical hydrogels, PDMAEA-Q gel (2-8-0.1), PNaAMPS gel (2.5-4-0.1), and PDMAAm gel (2-4-0.1), were illustrated. As microelectrode was moved in the solution, the potential values of these three curves were almost 0 . With inserting microelectrode from solution to bulk gel, the electrical potentials abruptly increase or drop to a stable positive and negative values for polyelectrolyte PDMAEA-Q gel and PNaAMPS gel, respectively. On the other hand, the electric potential of neutral gel, PDMAAm gel, was also shown with an average value of $-7.2 \pm 2.6 \mathrm{mV}$. Even though there are no certain charged groups on the PDMAAm polymer chain, a non-negligible negative potential of this gel was also shown. Why does this neutral gel show a small negative potential? Blyakhman et $\mathrm{al}^{35}$ considered this potential was introduced by the diffusion of $\mathrm{KCl}$ solution across the tip of the microelectrode. However, we thought the diffusion effect will not affect the 
gel potential value if the leakage $\mathrm{KCl}$ solution does not diffuse into the surface location of the reference electrode. Our results found that even though the concentration of filling $\mathrm{KCl}$ solution was decreased from $3 \mathrm{M}$ to $1 \mathrm{M}$, the measured potential value of hydrogel was invariant to filling $\mathrm{KCl}$ solution. The possible explanation for this negative potential is that some polar groups in PDMAAm chains, such as amide groups, would induce different ions distribution within the hydrogel. This small difference of ions distribution between gel and reference solution would also introduce a weak Donnan potential. According to Donnan equation ${ }^{36}$, we can easily calculate the concentration of mobile ions in hydrogel $\left(1.3 \times 10^{-5} \mathrm{M}\right)$, which is only a little higher than that concentration of the bulk solution $\left(10^{-5} \mathrm{M} \mathrm{NaCl}\right)$.
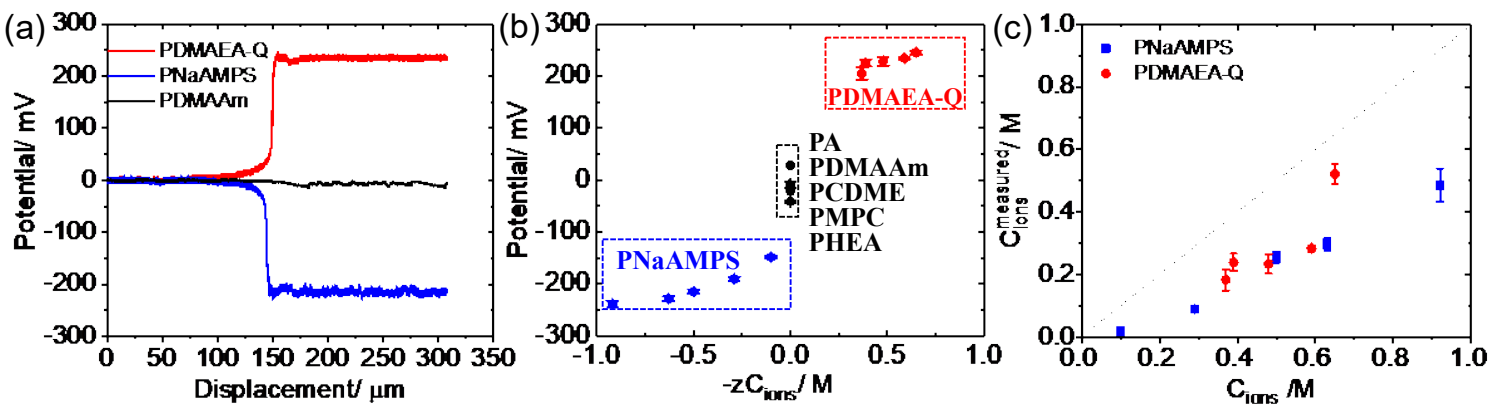

Fig. 2 Electrical potential of various hydrogels. (a) Typical potential-displacement curves for PDMAEA-Q, PNaAMPS and PDMAAm hydrogels. The potential was detected at bath solution of $10^{-}$ ${ }^{5} \mathrm{M} \mathrm{NaCl}$ solution; (b) Summary of electrical potential values at different in-feed ions concentration, $\mathrm{C}_{\text {ions, }} \mathrm{z}$ represents the charge number of counterions. (c) Comparison of measured counterions concentration to in-feed ions concentration. The measured concentration is much lower than that of in-feed counterions concentration.

By using this microelectrode technique, we could measure electrical potentials of various negative gels, positive gels, and neutral hydrogels, as shown in Fig. 2 (b). After considering the charge valence of counterions, $z$, and swelling ratio of hydrogels, $Q$, the ideal ions concentration of polyelectrolyte hydrogels could be nominalized by ${ }_{z} C_{\text {ions }}={ }_{z} C_{\text {ions }}^{0} / Q$, while $C_{\text {ions }}^{0}$ is the in-feed monomer concentration. From Fig. 2 (b), the absolute electric potential of PNaAMPS gels and PDMAEA-Q gels were gradually increased with the increase of charge density. This result is consistent with 
our previous study ${ }^{31}$. From the electrochemical equilibrium condition, the Donnan potential, $\Delta \phi$, is expressed by:

$$
\Delta \phi=\frac{R T}{z F} \ln \left(\frac{a_{i o n}^{S}}{a_{i o n}^{g}}\right)
$$

in which $z$ is the valence of the mobile ion in consideration, $R$ is the gas constant,

$T$ is the absolute temperature, $F$ is the Faraday constant, $a_{i o n}^{s}$ and $a_{i o n}^{g}$ are the activity of mobile ions in solution and gel. The activity of mobile ions $a_{i o n}$ is related to the activity coefficient $\gamma_{i o n}$ and the concentration $C_{i o n}$ as $a_{i o n}=\gamma_{i o n} C_{i o n}$ for each kind of ions.

As the concentration of buffer salt solution is quite low, the activity coefficient of $\mathrm{NaCl}$ solution is considered as $1, \gamma_{\text {ion }}^{S}=1$. Therefore, the true counterions concentration in bulk gel can be calculated from Eq. (2), as shown in Fig. 2 (c). Compared to in-feed counterions concentration, $C_{i o n s}=C_{0} / Q$, the measured counterions concentration of both PNaAMPS and PDMAEA-Q gels are much smaller than this value, indicating the effective counterions concentration is reduced due to the counterions condensation effect.

\subsection{Comparison of the gel mesh size with hydrodynamic diameter of protein}

The hydrogel is a kind of material consisting of 3D polymer networks as well as filled water. Inside the gel, the 3D networks were fixed by chemical or physical crosslinking points, or entangled chains to support their solid structure. If the mesh size $(\xi)$ corresponding to the distance between two adjacent cross-linked chains is much larger than hydrodynamic diameter of proteins, some proteins would be not only adsorbed on gel surface but also penetrated into the surface layer of the hydrogels.

According to Affine network model ${ }^{37}$, the shear modulus $G$ of the hydrogels, which the number density of strands inside the correlation volume is same as the overall number density of strands, can be roughly calculated by:

$$
G=E / 3=k_{B} T v_{e}
$$

where $v_{e}$ and $E$ are the number of network strands per unit volume and Young's modulus of networks, respectively; $k_{B}$, Boltzmann constant; $T$, absolute temperature. The density of elastic strands can be given by $v_{e}=1 / \xi_{0}^{3}$, here $\xi_{0}$ is the mesh size of 
the Gaussian chain. And we get:

$$
\xi_{0} \cong\left(k_{B} T / G\right)^{1 / 3}=\left(3 k_{B} T / E\right)^{1 / 3}
$$

If we assume the networks are uniformly deformed during swelling, the swollen mesh size $\xi_{\text {swollen }}$ of a network can be approximately given by:

$$
\xi_{\text {swollen }}=\xi_{0} \cdot \sqrt[3]{Q}
$$

From compression test, Young's moduli, E, of as-prepared hydrogels are easily determined from the slope of the stress-strain curve at small deformation (Supplementary information Fig. S3 and summarized in Table S3). Therefore, the real $\xi_{\text {real }}$ of hydrogels could be calculated after measuring $E$ and $Q$. On the other hand, the hydrodynamic diameters of BSA $\left(d_{B S A}\right)$ and lysozyme $\left(d_{\text {lysozyme }}\right)$ measured by DLS method at $10^{-5} \mathrm{M}$ solution were $8.17 \pm 0.85 \mathrm{~nm}$ and $1.23 \pm 0.56 \mathrm{~nm}$, respectively (Supplementary information Fig. S2).
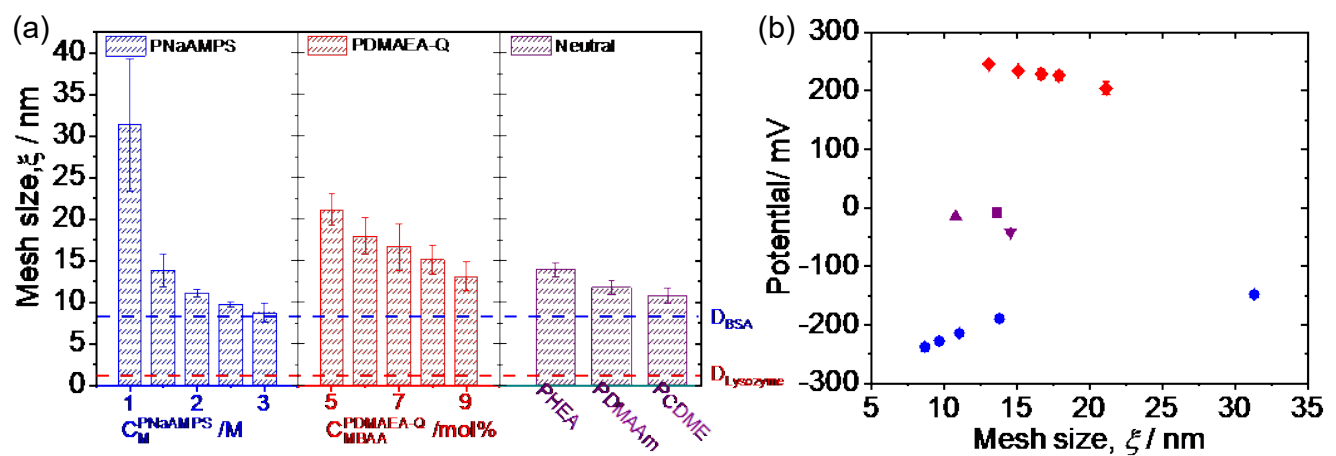

Fig. 3 (a) Calculation results of mesh size of three types of swollen hydrogels, negative hydrogel with different monomer concentration, positive hydrogel with different cross-linker concentration and neutral hydrogels. Compared to hydrodynamic diameter of BSA and lysozyme proteins, the mesh sizes of those gels are much larger than protein sizes. (b) The correlation between potentials and mesh sizes. For polyelectrolyte hydrogels, the mesh sizes and electrical potentials are changed at same time. Symbols at figures represent PDMAEA-Q $(\bullet), \operatorname{PNaAMPS}(\boldsymbol{0}), \operatorname{PDMAAm}(\boldsymbol{\square}), \operatorname{PHEA}$ $(\boldsymbol{\nabla})$, and PCDME $(\mathbf{\Delta})$ hydrogels.

Fig. 3 (a) shows mesh sizes of positive, negative and neutral hydrogels. By changing the concentration of cross-linkers or monomers, $\xi_{\text {swollen }}$ of hydrogel could be effectively adjusted. $\xi_{\text {swollen }}$ of PNaAMPS hydrogels is decreased with the increase of 
crosslinking density; meanwhile, $\xi_{\text {swollen }}$ of PDMAEA-Q hydrogels decreases when $C_{M}$ of hydrogel increases. Nevertheless, $\xi_{\text {swollen }}$ of those charged hydrogels are much larger than hydrodynamic diameters of BSA and lysozyme proteins. Compared to $d_{B S A}$ and $d_{l y s o z y m e}, \xi_{\text {swollen }}$ of two neutral hydrogels, PDMAAm, and PHEA hydrogels, are also large. This result indicates that some proteins may locate both surface and inside of bulk gels. In Fig. 3 (b), the dependency of the gel potential on mesh size was summarized, it could be found that the potential of neutral hydrogels was relative small, and there was no strong dependence between the potential and the mesh sizes. The absolute potentials of the polyelectrolyte hydrogels, however, were decreased with increasing of gel mesh size. Because the gel mesh size was corresponded to the charge density of the polyelectrolyte hydrogel, the small mesh size of a polyelectrolyte hydrogel indicated the high charge density and the large absolute potential value. From above analysis, it can be found that it is difficult to separate the electrical potential and the mesh size at the same time by changing monomer concentration or cross-linking densities.

\subsection{Evidence of protein distribution on gel surface and in bulk gel}

To clarify the location of proteins, some direct methods, such as ATR-FTIR spectroscopy and TEM observation, are necessary. IR technique had been used to study qualitative and quantitative information about adsorbed proteins on hydrophilic polymers ${ }^{38}$. In this study, hydrogels with absorbing oppositely charged proteins were adopted to analyze the surface structure of hydrogels. ATR spectra of PDMAEA-Q (29-0.1) gel with BSA proteins absorption are shown in Fig. 4 (a). (IR spectra of lysozyme absorption on PNaAMPS (2.5-4-0.1) gel are shown in Fig. S4.) Those spectra focus solely on the C-N stretching trends and reflect what is occurring within the hydrogel surface as peak intensity undergoes a variation from absorption of proteins. After absorbing proteins on the gel surface, there is an increase in absorbance of the C-N peak (1396 and $1240 \mathrm{~cm}^{-1}$ ). In addition to the $\mathrm{C}-\mathrm{N}$ absorbance changes, a slight shift in $\mathrm{C}=\mathrm{O}$ stretching modes are also found, $\mathrm{C}=\mathrm{O}$ stretching frequency of PDMAEA-Q gel is assigned at $1637 \mathrm{~cm}^{-1}$. When BSA proteins are absorbed, a blue shift of the $\mathrm{C}=\mathrm{O}$ stretching mode has been found at a frequency of $1626 \mathrm{~cm}^{-1}$. As the detective zone of the sample by using ATR method is up to a depth of $2.0 \mu \mathrm{m}$, the peaks variation 
reflected from ATR-IR spectra indicates that proteins are located at least in the gel close to the surface. On the contrary, the spectra of hydrogels with the same charges as proteins show no obvious protein absorption on the gel surface, as shown in Fig. S4 (b) and (c).

(a)

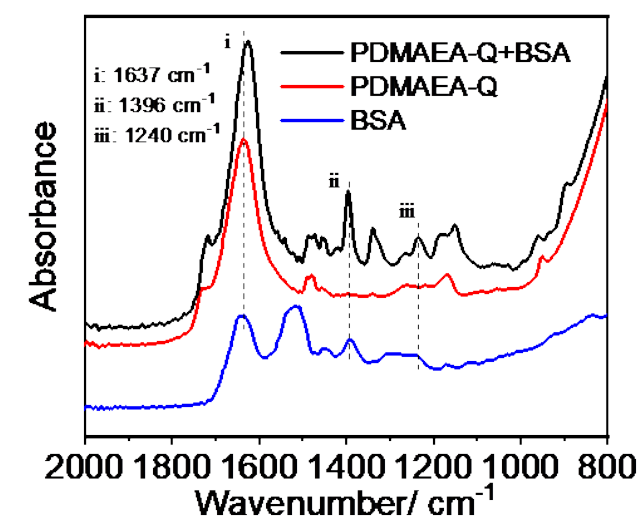

(b)

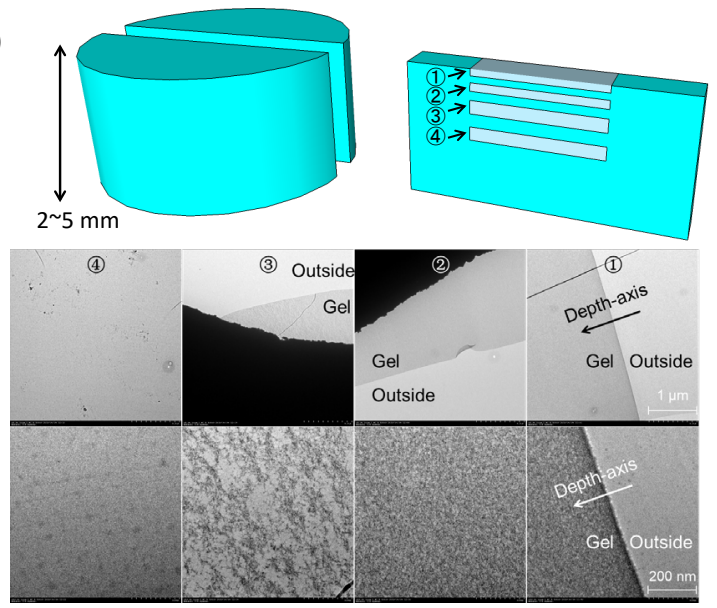

Fig. 4 (a) ATR-FTIR spectra of the BSA protein absorption on PDMAEA-Q (2-9-0.1) gel, $\xi / d_{B S A}=1.6$; The locations of the C-N peaks at BSA proteins were recorded to be $1396 \mathrm{~cm}^{-1}$ and $1240 \mathrm{~cm}^{-1}$, respectively from this spectrum. After absorbing proteins on gel surface, $\mathrm{C}=\mathrm{O}$ stretching peak decreases from 1637 to $1626 \mathrm{~cm}^{-1}$. (b) Schematic image of four cross-section regions for PDMAEA-Q/PAAm gel (2-9-0.1/2-0-0.1). From gel surface to bulk gel, four regions, (1)surface, 0 $\sim 20 \mu \mathrm{m}$; (2)bulk gel, $70 \sim 90 \mu \mathrm{m}$; (3)bulk gel, $140 \sim 160 \mu \mathrm{m}$; and (4) bulk gel, $190 \sim 210 \mu \mathrm{m}$ are illustrated. (c)TEM images showing proteins distributed at both surface and bulk gel. Observation at upward and bottom are magnified at $1 \mathrm{k}$ and $10 \mathrm{k}$ times with an applied accelerating voltage of $100 \mathrm{kV}$, respectively.

Further examination of protein location by TEM reveals insight into the behavior of protein absorption on gels. Since TEM imaging relies upon differences in electron density between the sample and the surrounding substrate, or presence of inorganic species that are concentrated. In our experiment, the proteins stained by phosphotungstic acid inside PDMAEA-Q gels could be easily detected. In Fig. 4 (c), TEM images of protein distribution are shown, the upper and the lower images are acquired at $1,000 \times$ and $10,000 \times$ magnifications, respectively. By choosing the four regions from the surface of PDMAEA-Q gel to the bulk gel at the cross-section, (1)0 
$20 \mu \mathrm{m}$,(2)70 $90 \mu \mathrm{m}$, (3) $140 \sim 160 \mu \mathrm{m}$, and (4)190 $210 \mu \mathrm{m}$, both protein distribution

513

514

515

516

517

518

520

521

522

523

524

525

526

527

528

and local density in bulk gel are obviously revealed. From those TEM images, proteins are randomly dispersed in both surface and bulk. Some minor aggregation is observed at region (3). With further penetrating to bulk gel, the density of absorbed proteins is decreased, such dark particles were very few at region (4). Apparently, some of the proteins are located inside the PDMAEA-Q gels. That means the protein absorption is also influenced by the mesh size of the hydrogel.

\subsection{Effect of the gel mesh size on the amount of potential absorption}

(a)

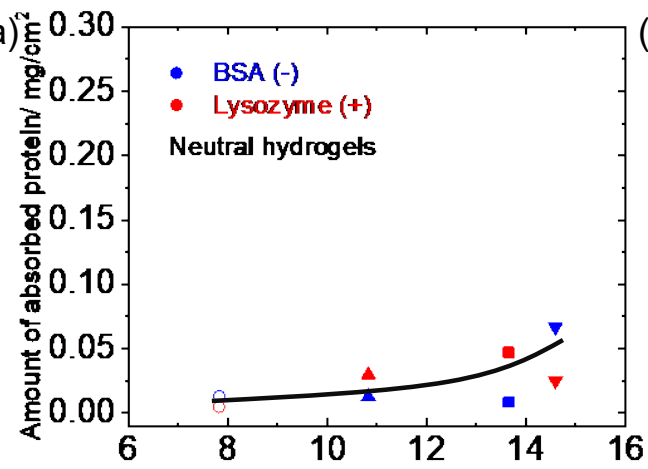

(c) $\stackrel{\Sigma}{E} 0.30 \quad \xi / \mathrm{nm}$

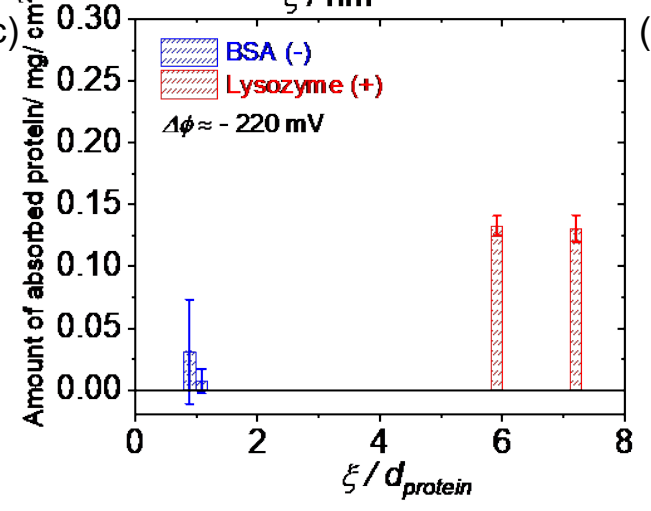

(b)

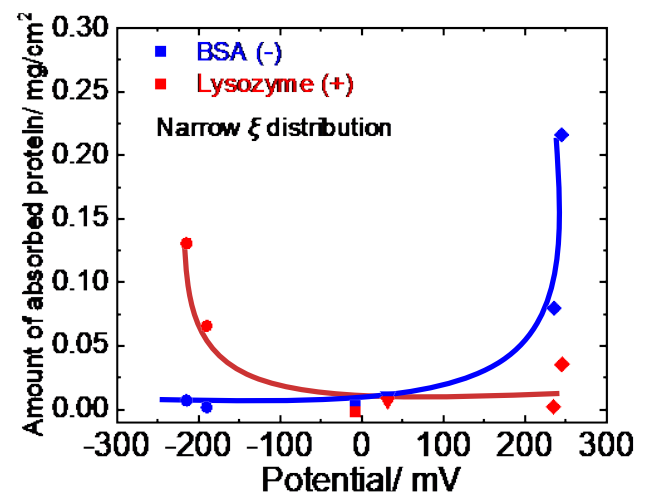

(d) E

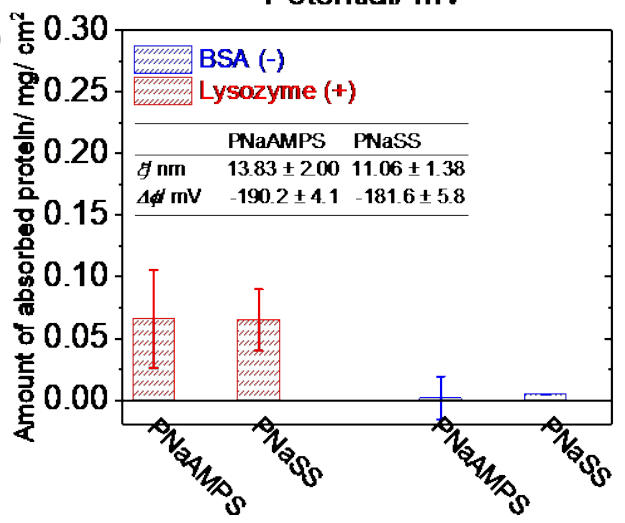

Fig. 5. (a) Effect of mesh size of neutral hydrogels on amount of protein absorption; (b) Amount of protein absorption on hydrogel with a narrow mesh sizes distribution from 10.6 to $15.1 \mathrm{~nm}$; (c) comparison of protein absorption for different mesh size but same electrical potential value, $\Delta \phi=$ $-220 \mathrm{mV}$; (d) comparison of protein absorption for different hydrogel with same mesh size and same potential value. Symbols at figures represent PDMAEA-Q $(\bullet), \operatorname{PNaAMPS}(\bullet), \operatorname{PDMAAm}(\boldsymbol{\square})$, $\operatorname{PHEA}(\boldsymbol{\nabla}), \operatorname{PCDME}(\boldsymbol{\Delta}), \operatorname{PMPC}(\square)$, and PA $(\bigcirc)$ hydrogels. 
surface and inside bulk gel if mesh size is much larger than hydrodynamic diameter of proteins. Namely, the amount of protein absorption on the gel are dominated by both electrical potentials and mesh size of the hydrogel. To further clarify which factor, $\xi$ or $\Delta \phi$, determine the amount of protein absorption, those two factors should be separately discussed.

(1) Neutral hydrogels, different mesh sizes $\xi$ :

The neutral hydrogels show a small potential value in the range of $\pm 50 \mathrm{mV}$, and the amount of protein absorption are relatively few for those neutral hydrogels. On the other hand, the amount of protein absorption is slightly dependency when the mesh size of those hydrogels is increased. On the other hand, with increasing the mesh sizes, the amount of protein absorption is gradually increased, as shown in Fig. 5 (a). In spite of little difference in electrical potentials, the protein absorption on neutral hydrogels is quite small and slightly dependent on the mesh size of networks. From this result, we know that the amount of protein absorption is dominated by osmotic pressure, and mesh size of neutral hydrogels is a crucial parameter to absorption behavior. However, the diffusion behavior of protein is beyond the scope of this work and will be presented elsewhere. In short, the mesh size of neutral hydrogels has little effect on protein absorption.

(2) Narrow $\xi$ distribution, different $\Delta \phi$ :

By choosing averaged $\xi_{\text {real }}$ from 10.6 to $15.1 \mathrm{~nm}$, the hydrogels with different $\Delta \phi$ are selected. The amount of protein absorption on those hydrogels is compared in Fig. 5 (b), points with blue and red color are represented of BSA and lysozyme proteins respectively. In this figure, most of BSA proteins are largely absorbed to positive hydrogels rather than neutral or negative hydrogels. Similarly, lysozyme proteins tend to absorb to negative hydrogels and abominate to neutral and negative hydrogels. In spite of some proteins penetrating into the surface layer of the hydrogels, the electrical potential of hydrogels seems a crucial role in tuning protein absorption behavior.

(3) Same $\Delta \phi$, different $\xi$ :

To further clarify the effect of gel mesh size on potential absorption, some polyelectrolyte gels with the same electrical potential value, i.e. the potential of 
PNaAMPS 2-10-0.1 gel and PNaAMPS 2.5-4-0.1 gel are -224.0 $\pm 11.3 \mathrm{mV}$ and -228.0 $\pm 4.1 \mathrm{mV}$ respectively, are selected. After analyzing mesh sizes of those two gels, 7.27 $\mathrm{nm}$ of PNaAMPS 2-10-0.1 gel and 8.86 nm of PNaAMPS 2.5-4-0.1 gel are found respectively. That means the size ratio, which is defined as the ratio of mesh size to protein diameter, $\xi / d_{\text {protein }}$, is quite different for PNaAMPS gels of 2-10-0.1 and 2.54-0.1. In spite of different size ratio, the protein absorption of lysozyme and BSA proteins seems no significant difference, as shown in Fig. 5 (c). Large protein absorption was observed at oppositely charged hydrogels to protein, indicating an influence of opposite charges in tuning protein absorption. Similarly, other hydrogels with the same potential value also show the same influence in Fig. S5 (Supplementary information). Thus, the influence of mesh size of charged hydrogels has little effect on protein absorption.

(4) Same $\Delta \phi$, same $\xi$ :

To demonstrate that the electrical potential of polyelectrolyte hydrogel is crucial to protein absorption, we prepare another anionic hydrogel, PNaSS gel (1-8-0.1), to learn the effect of macro-ions on protein absorption. The prepared PNaSS gels with almost the same mesh size and electrical potential value of PNaAMPS (1.5-4-0.1) gel are chosen to compare protein absorption, as shown in Fig. 5 (d). Even though the side functional groups of these two hydrogels are different, the amount of BSA or lysozyme protein absorption are almost same. That is, proteins preferably absorbed on oppositely charged hydrogels rather than likewise charged hydrogels. For negatively charged hydrogels, it seems that the macro-ion type has a little or no influence on protein absorption.

\subsection{Tunable protein absorption on hydrogel surface by electric potential}

To study how many the adsorbed proteins on the gel, we simply divide the amount of proteins into three parts, proteins distributed in gel, container wall, and solution. By determining the amount of the proteins in solution and container wall, the amount of attached proteins on hydrogel was easy to be calculated from Eq. 1. In our experiment, we found the number of adsorbed proteins on sample plates was very few $(-2.0 \pm 2.6 \mathrm{wt} \%$ of overall protein), indicating that most of the proteins were distributed in both solution 
and gel. As shown in Fig. 6 (a), the amount of absorbed BSA and lysozyme proteins per area on different kinds of hydrogels are illustrated, and the amount of absorbed proteins per volume is also shown in Fig. $\mathbf{S 6 .}$

(a) ${ }^{\mathrm{t}}$

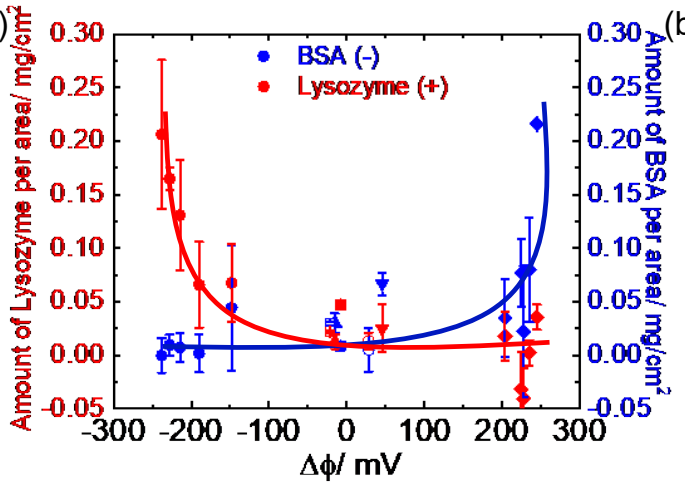

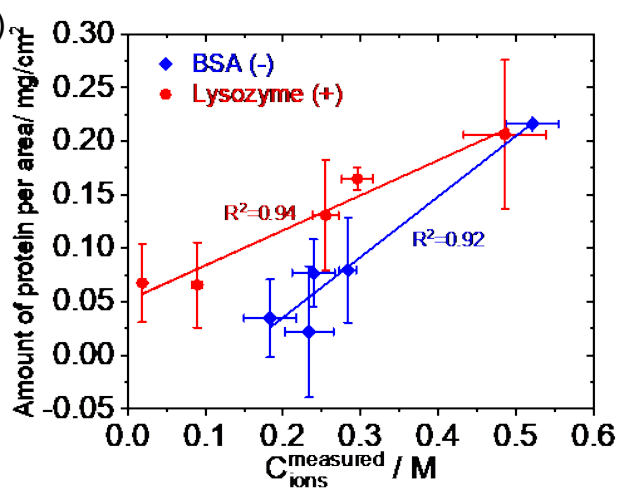

Fig. 6 (a) Amount of protein absorption per area for various hydrogels, such as PDMAEA-Q $(\diamond)$, PNaAMPS ( $\mathbf{0}), \operatorname{PDMAAm}(\boldsymbol{\square}), \operatorname{PHEA}(\boldsymbol{\nabla}), \operatorname{PCDME}(\boldsymbol{\Delta}), \operatorname{PMPC}(\square)$, and $\operatorname{PA}(\bigcirc)$ gels. The amount of adsorbed proteins on gel surface were calculated according to the equation, $m_{g e l}=m_{\text {total }}-$ $m_{\text {solution }}-m_{\text {plate }}$. The blue and red curves represent the protein absorption behavior of BSA and lysozyme on hydrogels, respectively. (b) The correlation between amount of protein absorption and measured charge concentration. The blue and red curves represent the absorption behavior of BSA proteins on PDMAEA-Q gels and the absorption behavior of lysozyme proteins on PNaAMPS gels, respectively.

It seems that protein absorption on the gel surface is tunable by the electrical potential of hydrogels. In details, lysozyme proteins were likely absorbed on the negative PNaAMPS hydrogels, and the amount of protein absorption was decreased with the increase of electric potential. When the potential value was around or larger than $0 \mathrm{mV}$, few or none of the lysozyme proteins were absorbed on the gel surface. Similarly, the BSA proteins were tended to absorb to positive PDMAEA-Q hydrogels, and there was no obvious protein absorption on the same charged PNaAMPS hydrogels. Inoue et al. also found that the amount of protein absorption on the surfaces of brush layers was determined from the combination of the electrostatic interaction force and the charge properties of the proteins. ${ }^{39}$ By combining the results in Fig. 2 (c) and Fig. 6 (a), the correlation between the amount of protein absorption and measured charge 
concentration is re-analyzed and shown in Fig. 6 (b). The absorption of lysozyme and BSA proteins on PNaAMPS and PDMAEA-Q gels are linearly increased with the measured counterions concentration. According to $\zeta$-potential results, $\zeta$-potential values of lysozyme and BSA protein solution were $34.81 \pm 4.16 \mathrm{mV}$ and $-22.13 \pm 4.26 \mathrm{mV}$, respectively. That means that proteins are likely absorbed on the different charged surface, and the amount of protein absorption is largely depended on both macroions valences and densities. Here, we consider that the absorbed proteins only distributed on the gel surface and no proteins diffuse into the bulk gel. But there is another problem, how are the proteins accumulated on the gel surface? In other words, whether the absorbed proteins are randomly distributed in the surface networks or stacked on the gel surface?

To answer this question, we calculated the thickness of protein layers, and then compare the mesh size, $\xi$, of the hydrogel with the hydrodynamic diameter of proteins, $d_{\text {protein }}$. Here, we assume the absorbed proteins are same as their crystal size, (1) All charged groups distribute in the bulk gel uniformly; and (2) all charges in bulk gel can absorb or repel proteins, and there are no counterions condensation behavior; (3) protein volume, $v_{0}$, is calculated by its dimensions. As a result, the $v_{0}$ of BSA and lysozyme proteins is $14 \times 4 \times 4 \mathrm{~nm}^{3}$ and $3 \times 3 \times 4.5 \mathrm{~nm}^{3}$, respectively. The thickness of the adsorbed protein layer, $h$, could be expressed by:

$$
A h=N_{A} n_{\text {protein }} \times v_{0}
$$

Thus, the thickness of the adsorbed protein layer could be calculated (Supplementary information Fig. S7). From these results, the largest thickness of absorbed proteins is up to $4.4 \mu \mathrm{m}$, which is quite large compared to the Debye length scale $\left(\sim 100 \mathrm{~nm}\right.$ in $10^{-5} \mathrm{M}$ solution). According to the results of the TEM images, the absorbed proteins are located on both the gel surface and inside the bulk gel (up to a depth of $200 \mu \mathrm{m})$. Thus, this analysis gives us further evidence that the absorbed proteins are randomly distributed in the gel network, and the amount of protein absorption are probably correlated the density of the oppositive charges in a polyelectrolyte network.

Additionally, we re-analyze the protein absorption against $\xi_{\text {real }}$ of those hydrogels 
in Fig. S8 (a) and (b). The results show that there is no obvious dependency between the amount of protein absorption and the mesh size.

Above all, even though the protein absorption is affected by $\xi_{\text {real }}$ of hydrogels, proteins absorption on polyelectrolyte hydrogels is dominative to hydrogel potentials. In other words, the amount of protein absorption on hydrogels are largely affected by the surface charges of the hydrogel.

\section{Conclusion}

In this work, the correlation between the electrical potential of hydrogels and the amount of charged protein absorption was investigated. Polyelectrolyte hydrogels, including PNaAMPS gel with negative macro-ions and PDMAEA-Q gels with positive macro-ions, were prepared by changing monomer concentration or cross-linking density. Neutral hydrogels, including PHEA and PDMAAm gels without any macroions groups, polyzwitterionic PCDME gel, and polyampholyte gels, were also chosen for protein absorption. By using the MET, electrical potentials of those polyelectrolyte and neutral hydrogels were systematically studied. Two charged proteins, BSA and lysozyme, exhibited the selective absorption on the charged hydrogels. That is, proteins preferably absorbed on oppositely charged hydrogels rather than likewise charged hydrogels. This selective absorption, dominated by electrostatic interaction, is a major issue in terms of the amount of protein absorption.

Considering the precision during calculating the protein absorption, we assessed the diffused proteins inside the bulk gel. To clarify the distribution of protein, the mesh size of these hydrogels was introduced. The mesh sizes of hydrogels were quite large compared with the dynamic diameter of proteins. Thus, the proteins might be located inside of the bulk gel. This deduction was further verified by the observation of ATRFTIR spectra and TEM images.

Despite the existence of diffused proteins in bulk gels, protein absorption on hydrogels was also dominated by the electrical potential. A comparison of potentials was considered in terms of the same mesh sizes, the amount of protein absorption was strongly dependent on potential values. On the other hand, hydrogels, which possess 
672 the same potential value but different mesh size, do not show an obvious difference in 673 protein absorption. The protein absorption on neutral gels slightly increased with 674 enlarging the mesh size, which further confirmed the weak dependence of protein 675 absorption on the mesh size. Additionally, hydrogels with both same potential value and mesh size show undistinguished appearance in protein absorption although they have different macro-ions.

Based on the above results, the protein absorption on the charged hydrogels is assessed successfully. With potential values and mesh sizes taken into account, protein absorption on charged hydrogels can be compared in terms of protein charges. This will shed light on the protein absorption of charged hydrogels. Hydrogen bonds and hydrophobic interaction of hydrogels are also needed in the future work of understanding and predicting the protein absorption on different kinds of hydrogels. Our findings should be relevant to understand the mechanism of protein aggregation in solution such as binding or drug delivery.

\section{Supplementary information}

$\zeta$-potential of hydrogels and proteins, hydrodynamic diameter of proteins, swelling ratio and calculated counterions concentration, stress-strain curves of hydrogels, Young's modulus of hydrogels, ATR-FTIR spectra of hydrogels and proteins, comparison of the amount of protein absorption at same potential value, the amount of protein absorption per volume, calculation of protein layer at gel surface, the dependence of the amount of adsorbed proteins on mesh size of hydrogels.

\section{Acknowledgment}

This research was financially supported by founds from Grant-in-Aid for Scientific Research (S) (No. 17H06144). The authors thank Prof. JianPing Gong for her helpful discussion and suggestion, as well as Dr. Kazuya Furusawa, Dr. Min Yao, Dr. Taolin Sun, Dr. Daniel R. King, Dr. Tasuku Nakajima, Mr. Kazuki Tanaka, Mr. Yunzhou Guo for their kind discussion and help. 
702

703

704

705

706

707

708

709

710

711

712

713

714

715

716

717

718

719

720

721

722

723

\section{Reference}

(1) Kolewe, K. W.; Dobosz, K. M.; Rieger, K. A.; Chang, C. C.; Emrick, T.; Schiffman, J. D. Antifouling Electrospun Nanofiber Mats Functionalized with Polymer Zwitterions. ACS Appl. Mater. Interfaces 2016, 8 (41), 27585-27593. https://doi.org/10.1021/acsami.6b09839.

(2) Isık, T.; Horzum, N.; Yıldız, H.; Liedberg, B.; Demir, M. M. Utilization of Electrospun Polystyrene Membranes as a Preliminary Step for Rapid Diagnosis. Macromol. Mater. Eng. 2016, 301 (7), 827-835. https://doi.org/10.1002/mame.201600127.

(3) Ma, H.; Hyun, J.; Stiller, P.; Chilkoti, A. "Non-Fouling” Oligo(Ethylene Glycol)Functionalized Polymer Brushes Synthesized by Surface-Initiated Atom Transfer Radical Polymerization. Adv. Mater. 2004, 16 (4), 338-341. https://doi.org/10.1002/adma.200305830.

(4) Qiu, Y.; Park, K. Environment-Sensitive Hydrogels for Drug Delivery. Adv. Drug Deliv. Rev. 2012, 64 (SUPPL.), 49-60. https://doi.org/10.1016/j.addr.2012.09.024.

(5) Li, L.; Wang, Y.; Pan, L.; Shi, Y.; Cheng, W.; Shi, Y.; Yu, G. A Nanostructured Conductive Hydrogels-Based Biosensor Platform for Human Metabolite Detection. Nano Lett. 2015, 15 (2), 1146-1151. https://doi.org/10.1021/nl504217p.

(6) Balakrishnana, B.; Mohantyb, M.; Umashankarc, P. R.; Jayakrishnana, A. Anti-Bacterial Properties of an in Situ Forming Hydrogel Based on Oxidized Alginate and Gelatin Loaded with Gentamycin. Biomaterials 2005, 26 (3), 6335-6342. https://doi.org/10.1016/j.biomaterials.2005.04.012.

(7) Nonoyama, T.; Wada, S.; Kiyama, R.; Kitamura, N.; Mredha, M. T. I.; Zhang, X.; Kurokawa, T.; Nakajima, T.; Takagi, Y.; Yasuda, K.; et al. Double-Network Hydrogels Strongly Bondable to Bones by Spontaneous Osteogenesis Penetration. Adv. Mater. 2016, 6740-6745. https://doi.org/10.1002/adma.201601030.

(8) Baier, G.; Costa, C.; Zeller, A.; Baumann, D.; Sayer, C.; Araujo, P. H. H.; Mailänder, V.; Musyanovych, A.; Landfester, K. BSA Adsorption on Differently Charged Polystyrene Nanoparticles Using Isothermal Titration Calorimetry and the Influence on Cellular Uptake. Macromol. Biosci. 2011, 11 (5), 628-638. https://doi.org/10.1002/mabi.201000395.

(9) Hipkiss, A. R. Accumulation of Altered Proteins and Ageing: Causes and Effects. Exp. 
Gerontol. 2006, 41 (5), 464-473. https://doi.org/10.1016/j.exger.2006.03.004.

(10) Thevenot, P.; Hu, W.; Tang, L. Surface Chemistry Influences Implant Biocompatibility. Curr. Top. Med. Chem. 2008, 8 (4), 270-280.

(11) Ekblad, T.; Andersson, O.; Tai, F. I.; Edeith, T.; Liedberg, B. Lateral Control of Protein Adsorption on Charged Polymer Gradients. Langmuir 2009, 25 (6), 3755-3762. https://doi.org/10.1021/la803443d.

(12) Lundberg, P.; Bruin, A.; Klijnstra, J. W.; Nyström, A. M.; Johansson, M.; Malkoch, M.; Hult, A. Poly(Ethylene Glycol)-Based Thiol-Ene Hydrogel Coatings-Curing Chemistry, Aqueous Stability, and Potential Marine Antifouling Applications. ACS Appl. Mater. Interfaces 2010, 2 (3), 903-912. https://doi.org/10.1021/am900875g.

(13) Zhao, C.; Zhao, J.; Li, X.; Wu, J.; Chen, S.; Chen, Q.; Wang, Q.; Gong, X.; Li, L.; Zheng, J. Probing Structure-Antifouling Activity Relationships of Polyacrylamides and Polyacrylates. Biomaterials 2013, 34 (20), 4714-4724. https://doi.org/10.1016/j.biomaterials.2013.03.028.

(14) Rana, D.; Matsuura, T. Surface Modifications for Antifouling Membranes. Chem. Rev. 2010, 110 (4), 2448-2471. https://doi.org/10.1021/cr800208y.

(15) Beltrán-Osuna, Á. A.; Cao, B.; Cheng, G.; Jana, S. C.; Espe, M. P.; Lama, B. New Antifouling Silica Hydrogel. Langmuir 2012, 28 (25), 9700-9706. https://doi.org/10.1021/la301561j.

(16) Ma, H.; Wells, M.; Beebe, T. P.; Chilkoti, A. Surface-Initiated Atom Transfer Radical Polymerization of Oligo(Ethylene Glycol) Methyl Methacrylate from a Mixed Self-Assembled Monolayer on Gold. Adv. Funct. Mater. 2006, 16 (5), 640-648. https://doi.org/10.1002/adfm.200500426.

(17) Ma, H.; Li, D.; Sheng, X.; Zhao, B.; Chilkoti, A. Protein-Resistant Polymer Coatings on Silicon Oxide by Surface-Initiated Atom Transfer Radical Polymerization. Langmuir 2006, 22 (8), 3751-3756. https://doi.org/10.1021/la052796r.

(18) Ma, H.; Hyun, J.; Stiller, P.; Chilkoti, A. "Non-Fouling” Oligo(Ethylene Glycol)Functionalized Polymer Brushes Synthesized by Surface-Initiated Atom Transfer Radical Polymerization. Adv. Mater. 2004, 16 (4), 338-341. https://doi.org/10.1002/adma.200305830.

(19) Young, C. D.; Wu, J. R.; Tsou, T. L. High-Strength, Ultra-Thin and Fiber-Reinforced PHEMA Artificial Skin. Biomaterials 1998, 19 (19), 1745-1752. https://doi.org/10.1016/S01429612(98)00083-0. 
(20) Schmedlen, R. H.; Masters, K. S.; West, J. L. Photocrosslinkable Polyvinyl Alcohol Hydrogels That Can Be Modified with Cell Adhesion Peptides for Use in Tissue Engineering. Biomaterials 2002, 23 (22), 4325-4332. https://doi.org/10.1016/S0142-9612(02)00177-1.

(21) Dobbins, S. C.; McGrath, D. E.; Bernards, M. T. Nonfouling Hydrogels Formed from Charged Monomer Subunits. J. Phys. Chem. B 2012, 116 (49), 14346-14352. https://doi.org/10.1021/jp307588b.

(22) Wang, J.; Sun, H.; Li, J.; Dong, D.; Zhang, Y.; Yao, F. Ionic Starch-Based Hydrogels for the Prevention of Nonspecific Protein Adsorption. Carbohydr. Polym. 2015, 117, 384-391. https://doi.org/10.1016/j.carbpol.2014.09.077.

(23) Chen, S.; Jiang, S. A New Avenue to Nonfouling Materials. Adv. Mater. 2008, 20 (2), 335338. https://doi.org/10.1002/adma.200701164.

(24) Ostuni, E.; Chapman, R. G.; Holmlin, R. E.; Takayama, S.; Whitesides, G. M. A Survey of Structure-Property Relationships of Surfaces That Resist the Adsorption of Protein. Langmuir 2001, 17 (18), 5605-5620. https://doi.org/10.1021/la010384m.

(25) Jiang, D.; Liu, Z.; He, X.; Han, J.; Wu, X. Polyacrylamide Strengthened Mixed-Charge Hydrogels and Their Applications in Resistance to Protein Adsorption and Algae Attachment. RSC Adv. 2016, 6 (53), 47349-47356. https://doi.org/10.1039/C6RA05312B.

(26) Jian Ping Gong, Naoki Hirota, Akira Kakugo, Tetsuharu Narita, and Y. O. Effect of Aspect Ratio on Protein Diffusion in Hydrogels. J. Phys. Chem. B 2000, 104 (42), 9904-9908. https://doi.org/10.1021/jp001438o.

(27) Sassi, A. P.; Blanch, H. W.; Prausnitz, J. M. Phase Equilibria for Aqueous Protein/Polyelectrolyte Gel Systems. AIChE J. 1996, 42 (8), 2335-2353. https://doi.org/10.1002/aic.690420823.

(28) Smith, M. H.; Lyon, L. A. Tunable Encapsulation of Proteins within Charged Microgels. Macromolecules 2011, 44 (20), 8154-8160. https://doi.org/10.1021/ma201365p.

(29) Gong, J. P.; Komatsu, N.; Nitta, T.; Osada, Y. Electrical Conductance of Polyelectrolyte Gels. J. Phys. Chem. B 1997, 101 (5), 740-745. https://doi.org/10.1021/jp963059u.

(30) Manning, G. S. Limiting Laws and Counterion Condensation in Polyelectrolyte Solutions I . Colligative Properties. 1969, 924 (May 2013). https://doi.org/10.1063/1.1672157.

(31) Guo, H.; Kurokawa, T.; Takahata, M.; Hong, W.; Katsuyama, Y.; Luo, F.; Ahmed, J.; 
Nakajima, T.; Nonoyama, T.; Gong, J. P. Quantitative Observation of Electric Potential Distribution of Brittle Polyelectrolyte Hydrogels Using Microelectrode Technique. Macromolecules 2016, 49 (8), 3100-3108. https://doi.org/10.1021/acs.macromol.6b00037.

(32) Sun, T. L.; Kurokawa, T.; Kuroda, S.; Ihsan, A. Bin; Akasaki, T.; Sato, K.; Haque, M. A.; Nakajima, T.; Gong, J. P. Physical Hydrogels Composed of Polyampholytes Demonstrate High Toughness and Viscoelasticity. Nat. Mater. 2013, 12 (10), 932-937. https://doi.org/10.1038/nmat3713.

(33) Takahata, T.; Hayashi, M.; Ishikawa, T. SK4/IK1-like Channels Mediate TEA-Insensitive, Ca2+-Activated K+ Currents in Bovine Parotid Acinar Cells. Am. J. Physiol. Cell Physiol. 2003, 284 (1), C127-44. https://doi.org/10.1152/ajpcell.00250.2002.

(34) Zhou, C.; Heath, D. E.; Rahim, A.; Sharif, M.; Rayatpisheh, S.; Oh, B. H. L.; Rong, X.; Beuerman, R.; Chan-park, M. B. High Water Content Hydrogel With Super High Refractive Index. Macromol. Biosci. 2013, 13, 1485-1491. https://doi.org/10.1002/mabi.201300191.

(35) Blyakhman, F. A.; Safronov, A. P.; Zubarev, A. Y.; Shklyar, T. F.; Makeyev, O. G.; Makarova, E. B.; Melekhin, V. V.; Larrañaga, A.; Kurlyandskaya, G. V. Polyacrylamide Ferrogels with Embedded Maghemite Nanoparticles for Biomedical Engineering. Results Phys. 2017, 7, 3624-3633. https://doi.org/10.1016/j.rinp.2017.09.042.

(36) F.G.Donnan. The Theory of Membrane Equilibrium and Membrane Potential in the Presence of a Non-Dialyzable Electrolyte. A Contribution to Physical-Chemical Physiology. Zeitschrift für Elektrochemie und Angew. Phys. Chemie 1911, 17 (10), 572-581. https://doi.org/10.1016/0376-7388(94)00297-C.

(37) Rubinstein, M.; Colby, R. H. Polymer Physics; Oxford University Press, 2003.

(38) Castillo, E. J.; Koenig, J. L.; Anderson, J. M. Characterization of Protein Adsorption on Soft Contact Lenses. IV. Comparison of in Vivo Spoilage with the in Vitro Adsorption of Tear Proteins. Biomaterials 1986, 7 (2), 89-96. https://doi.org/10.1016/0142-9612(86)90062-1.

(39) Sakata, S.; Inoue, Y.; Ishihara, K. Precise Control of Surface Electrostatic Forces on Polymer Brush Layers with Opposite Charges for Resistance to Protein Adsorption. Biomaterials 2016, 105, 102-108. https://doi.org/10.1016/j.biomaterials.2016.07.043. 